\section{LA CARTA A LOS ESPAÑOLES AMERICANOS, DE JUAN PABLO VISCARDO. APORTES PARA EL ESTUDIO DEL SIGLO XVIII HISPANOAMERICANO}

\author{
MÓNICA ELSA SCARANO \\ CELEHIS, FH, UNMdP (Argentina) \\ mscarano@mdp.edu.ar
}

Mónica Elsa Scarano

Mónica Elsa Scarano es doctora en Letras de la Universidad de Buenos Aires y profesora y licenciada en Letras de la Universidad Nacional de Mar del Plata (Argentina). Es profesora titular de Literatura y Cultura Latinoamericana I y seminarios de grado y posgrado de ese área del Departamento de Letras de la Facultad de Humanidades de la UNMdP. Es docenteinvestigadora del Centro de Letras Hispanoamericanas (CELEHIS). Sus publicaciones están dedicadas especialmente al estudio del ensayo de interpretación cultural y la crónica urbana del siglo XIX y principios del XX. Correo electrónico: mscarano@mdp.edu.ar

\title{
RESUMEN
}

La Carta a los españoles americanos del ex jesuita expulso peruano, Juan Pablo Viscardo y Guzmán es un texto de alta significación para estudiar el proceso emancipatorio de la América Hispana. Olvidada durante más de un siglo y poco estudiada antes del siglo XX, la epístola nos permite problematizar el ya complejo siglo XVIII hispanoamericano. En nuestro trabajo nos detendremos en algunas cuestiones que atraviesan el texto y que nos permiten repensar ese período: la tradición epistolar colonial, el ideario ilustrado y su peculiar cruce con el patriotismo criollo, la literatura de los jesuitas en América y las proyecciones hacia la Emancipación americana.

Palabras clave: Carta a los españoles americanos, Viscardo, siglo XVIII, América.

\section{ABSTRACT}

The Letter to the Spanish Americans, written by the Peruvian ex Jesuit expelled, Juan Pablo Viscardo y Guzmán, is a remarkable text to study the emancipatory process in Hispanic America. Forgotten during more than a century and understudied before the twentieth century, the epistle allows us to problematize the already complex Hispanic American eighteenth century. In our paper, we will consider with particular attention some issues that cross along the text and help us to rethink that period: the colonial epistolary tradition, the illustrated ideology and its peculiar crossing with the Creole patriotism, the Jesuit literature in America and the projections to the American emancipation.

Keywords: Letter to American Spaniards, Viscardo, Hispanic XVIII, America.

El siglo XVIII hispanoamericano ofrece por su complejidad serias dificultades a la hora de señalar categorías en la prosa o de articular una caracterización coherente. Por esta razón, esa centuria se ha convertido en nuestro continente, como señala Karen Stolley, en «una tierra literaria de nadie», especialmente en lo relativo a la prosa, un verdadero «abismo más que un puente entre el Barroco colonial y el Romanticismo del siglo XIX»
(Stolley, 2006, p. 355) que, no obstante, se nos presenta hoy como un reto poco estudiado y mucho menos leído hasta nuestros días. Si la centuria anterior termina con la muerte de tres grandes autores del barroco colonial: Sor Juana Inés de la Cruz (1695), Juan del Valle y Caviedes (1697) y don Carlos de Sigüenza y Góngora (1700), el siglo que nos ocupa se cierra con la muerte de una figura emblemática, el abate Juan Pablo Viscardo y Guzmán
La Carta a los españoles americanos,
de Juan Pablo Viscardo. Aportes
para el estudio del siglo XVIII
hispanoamericano

MÓNICA ELSA SCARANO 


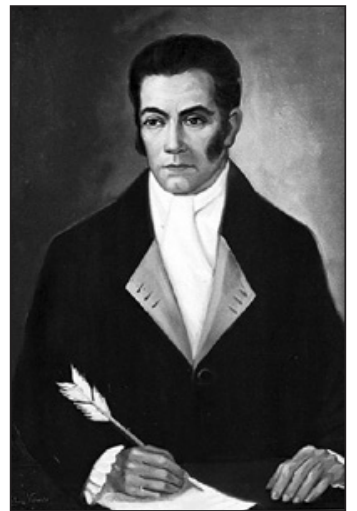

Retrato de Juan Pablo Viscardo siglo XIX

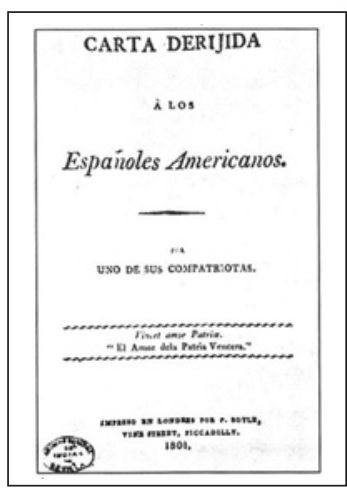

1

Juan Pablo Viscardo y Guzmán nació el 26 de junio de 1748 en la villa de Pampacolca, situada en un próspero distrito del departamento de Arequipa. Poco se conoce acerca de su infancia y la de José Anselmo, su hermano, también novicio jesuita y expulsado como aquel. Su familia tenía propiedades en el valle de Majes; allá está ubicada la hacienda de Chancán, donde pasó al parecer buena parte de su infancia. Cuando ingresaron a la Compañía de Jesús, los hermanos Viscardo fueron enviados al Colegio San Bernardo en el Cusco, y tras dos años de prueba pasaron al colegio Máximo de la Transfiguración para seguir los estudios de Humanidades y Filosofía. Sin duda la estadía en la capital incaica los marcó definitivamente por el ambiente tan especial de esa ciudad histórica. Su padre, Gaspar, murió inesperadamente poco antes de la expulsión de los jesuitas. Una vez desterrados en Italia, los hermanos dejaron los hábitos con la esperanza de que así se allanaría su regreso al Perú,

La Carta a los españoles americanos, de Juan Pablo Viscardo. Aportes para el estudio del siglo XVIII hispanoamericano

MÓNICA ELSA SCARANO

(1748-1798), ex jesuita peruano -arequipeño${ }^{1-}$, expulso, quien pasó sus últimos años en Londres, bajo la protección del Ministerio de Asuntos Exteriores, y con la sorprendente difusión de su famosa epístola pública de carácter incendiario. En efecto, Viscardo nos legó un manifiesto panfletario de gran trascendencia en la historia cultural de América Latina y que cumplió un rol fundamental en el proceso revolucionario que conduciría a la independencia de varios territorios de América: la Carta dirigida a los españoles americanos que terminó de escribir en Londres en 1791 y que fue publicada, ya muerto su autor y a instancias del patriota venezolano Francisco de Miranda, en francés, con el título: Lettre aux Espagnols-Américains, y con un pie de imprenta falso de Filadelfia, en 1799, para evitar dificultades en la divulgación del mensaje secesionista.

Los avatares del largo proceso de escritura de la epístola, que no fue un texto improvisado ni escrito a vuelapluma -contrariamente a lo que se podría pensar por su carácter intem-

lo que nunca sucedió. Anselmo se casó, tuvo una hija y murió en 1786. Juan Pablo pasó su exilio europeo en Italia e Inglaterra y murió en Londres el 10 de febrero de 1798 .

2

Las citas textuales de la "Carta a los españoles americanos» están extraídas de la siguiente edición: Juan Pablo Viscardo y Guzmán (2004), que reproduce la versión publicada en España en 1801, pero con ortografía y puntuación modernizadas. Cabe señalar que inicialmente la Carta fue escrita en español y el propio Viscardo la tradujo al francés. Además, los dos manuscritos existentes de ese documento están en ese idioma. Uno de ellos formó parte de los manuscritos que revisó y completó entre 1791 y 1792 y que presentó a "su protector», Sir James Bland Burges, el subsecretario de Estado británico, poco después de su arribo a Londres. Una década más tarde, al editar las dos versiones, la francesa y la española, Francisco de Miranda introdujo leves cambios muy significativos como la inserción en las notas de una larga lista de jesuitas exiliados y una extensa cita de Bartolomé de Las Casas, a quien Viscardo admiraba profundamente. En 1801, Miranda propició la traducción de la Carta al es- pañol y la publicó en Londres, titulándola Carta derijida [sic] a los españoles americanos. En 1806, cuando Miranda llegó a Venezuela con una pequeña expedición, repartió copias del panfleto en algunas islas del Caribe. Dos años después, la incluyó como apéndice en inglés, al costear una colección de documentos relacionados con su expedición, con la convicción de que ese "pequeño tratado» contribuiría en la tarea emancipatoria más que los discursos y declaraciones sobre España y Sudamérica. Efectivamente esta publicación causó una enorme impresión en Gran Bretaña.

3

José Gabriel de Condorcanqui (Túpac Amaru II), cacique de Tungasuca (Perú), había desatado en 1780 una rebelión para liberar a los habitantes originarios de esa región de la esclavitud de España y recuperar el antiguo imperio de sus antepasados. La rebelión fue sofocada y sus líderes, ejecutados. Según Viscardo, este fracaso se debió en gran parte al "recíproco celo» de las razas que habitaban el Perú, un serio obstáculo para la lucha contra el régimen colonial. Ya en Europa, Viscardo leyó en varias cartas procedentes de la América del Sur que el levantamiento abarcaba toda la

pestivo y apasionado-, así como las ediciones posteriores que colaboraron para su difusión -en español en 1801 y en inglés en 1808-, revelan su ubicación en la bisagra de los dos siglos (XVIII y XIX) ${ }^{2}$. En su exilio italiano, desde 1768, y durante sus estadías en Londres (entre 1782 y 1784, con su hermano, y ya fallecido éste, solo, entre 1791 y 1798), el joven peruano impulsado por las noticias de la rebelión de Túpac Amaru II en $1780^{3}$, se propuso establecer relaciones con los diplomáticos británicos ${ }^{4}$ y en los últimos años de su vida, fijó su residencia en Londres, donde fue un agente pagado por el Ministerio de Asuntos Exteriores británico ${ }^{5}$ En esos años escribió numerosos escritos -algunos de ellos con el seudónimo Paolo Rossi-, informes, cartas y ensayos sobre la situación socio-económica del Perú y sobre la manera más conveniente de liberar al país del dominio de la Corona española, solicitando el envío de una fuerza expedicionaria británica a la América del Sur para lograr una inmediata proclamación de la independencia.

región serrana del virreinato del Perú y que en Charcas y Quito existían movimientos separatistas semejantes. El ex jesuita alentaba una expedición naval británica para capturar el puerto de Buenos Aires, con la esperanza de que ello colaboraría a la liberación de su tierra natal. Finalmente ese plan se vio frustrado por cambios en el gobierno británico y por la firma de la paz entre España y Gran Bretaña, tras la declaración de guerra entre Francia y España, en 1793. Lo que queda claro hacia 1793 es la abierta oposición de Viscardo al estado revolucionario francés y sus crímenes y atropellos, sin que esto signifique desconocer la deuda de los angloamericanos y de los españoles americanos con la $\mathrm{Re}$ volución de Francia, a la cua reconoció siempre como un acontecimiento que conmocionó a todo el género humano.

Ya exiliado en Italia, en 1781, le envió varias cartas a John Udny, cónsul británico en Leg horn, en las que le comunicaba la noticia del levantamiento de Túpac Amaru II, señalaba el momento propicio para ganar la independencia de Hispanoamérica y ofrecía sus servicios al gobierno británico para ayudar a liberar al Perú, presentándolo como un atractivo mercado para los productos británicos (Simmons, 1983, p. 24). Víctima él mismo del despotismo español, se sumaba as al descontento de los españoles americanos con el régimen $\mathrm{CO}^{-}$ lonial y sus tiranías, especialmente por la exclusión de los criollos (los españoles nacidos en el Nuevo Mundo) de los puestos más altos de la lglesia y el Estado. A menudo incluso las reivindicaciones de indios, mestizos y mulatos tenían a los criollos como líderes naturales, como es el caso del mismo Viscardo, en el orden ideológico.

Entre junio de 1782 y marzo de 1784, los Viscardo residieron en Londres, donde recibían una modesta subvención del Ministerio de Asuntos Exteriores británico. En 1790, Francis Osborne, el quinto duque de Leeds y ministro de Asuntos Exteriores, ordenó a los representantes británicos en el norte de Italia que entablaran relaciones con Paolo Rossi, alias de Juan Pablo Viscardo y Guzmán. Éste causó tan buena impresión a los funcionarios, que pudo negociar ventajosamente su colaboración y obtener una buena retribución por sus servicios, suficiente para vivir cómodamente en Londres. Llegó a esa ciudad en marzo de 1791 y permaneció allí hasta su muerte. 
Justamente para colaborar con tal empresa terminó de escribir en 1791 su Carta dirigida a los españoles americanos, confiando en despertar el entusiasmo patriótico en la nobleza criolla y el clero, principales prodestinatarios y paradestinatarios de la Carta ${ }^{6}$, hasta convencerlos de aceptar a sus liberadores británicos. Fracasado este proyecto, se dedicó a trazar un análisis profundo del gobierno despótico que se impuso durante los tres siglos de colonialismo español en la América española, y de las desigualdades del comercio transatlántico. Viscardo murió sin haber visto publicados sus escritos, ni la Carta ni sus otros ensayos extensos ${ }^{7}$, pero siendo tal vez consciente de ello, en su lecho de muerte, confió su "paquete de papeles» a Rufus King, ministro plenipotenciario de los Estados Unidos en Londres, con la petición de publicarlos para su honra y la dicha del mundo. King se los prestó a Miranda, residente por ese tiempo en esa capital, quien fue el futuro responsable de las primeras ediciones de la Carta. Inmediatamente el documento llamó la atención e impulsó a muchos patriotas y revolucionarios a comprometerse con la lucha por la independencia americana. Luego desapareció por completo, relegados su autor y la Carta al olvido, al postergarse la independencia del Perú. Y aunque fue publicada por entregas en el país del autor, en 1822, casi no obtuvo reconocimiento, excepto la mención que hace de él Andrés Bello en su silva americana «Alocución a la poesía» (1823). Recién en el siglo $\mathrm{XX}$, la Carta se volvió a publicar, primero en París, luego en Buenos Aires y por último en Perú. Desde entonces y merced también a los estudios del paso de los jesuitas expulsos por Italia, se reavivó el interés tanto por la vida, el contexto y la formación profesional del autor como por su obra.

Otras razones nos permiten comprender este prolongado y aparente desinterés por la obra del arequipeño. A las investigaciones sobre el autor llevadas a cabo por dos eruditos jesuitas, el peruano Rubén Vargas Ugarte (1954) y el catalán Miguel Batllori (1953), que impulsaron la recuperación histórica de su fi-

6 Utilizamos la clasificación de los destinatarios del discurso político propuesta por Eliseo Verón (1987, pp. 16-18). En el juego discursivo que se plantea en todo discurso

gura y de sus escritos, se sumó el decisivo descubrimiento del historiador norteamericano Merle E. Simmons del "paquete de papeles» que Viscardo le confió a Rufus King ${ }^{8}$. Este hallazgo, junto con el de otras copias de la Carta y la publicación de las obras completas de Viscardo, significó un paso muy importante para el estudio de la trayectoria intelectual del peruano9. Como lo ha señalado David Brading, esto colaboró en forma decisiva para cambiar la percepción que se tenía de este autor, en la medida en que puso en evidencia que no fue un mero precursor de la independencia sino «una de las principales figuras de la Ilustración hispánica» (2004, p. 11), discípulo de Montesquieu y de Adam Smith.

\section{Entre la epístola colonial y el discurso polí- tico moderno}

Viscardo adjuntó su intensa y apasionada epístola, ya traducida al francés, en una carta dirigida a Sir Bland Burges del 15 de setiembre de 1791. En ella exhortaba a sus «hermanos y compatriotas»-tal, el inédito incipit de la Carta- a rebelarse contra el régimen colonial español que los oprimía. Este texto, a diferencia de los otros escritos coetáneos del autor, se caracterizaba por ser un verdadero manifiesto político emancipatorio, con un fuerte tono panfletario, diseñado para ser distribuido durante las expediciones de la marina británica en el caso de que éstas llegaran a la América española. En el manifiesto que precedía a la carta, el autor admitía su posible efecto insurreccional y por ello advertía que sólo debía ser distribuida en caso de una guerra entre España y Gran Bretaña, situación que no estaba lejos de poder concretarse por esos años.

Como lo ha planteado Luis Hachim Lara en su interesante estudio sobre el texto viscardino (2000), desde el punto de vista estrictamente genérico, esta epístola reconoce una larga tradición retórica colonial con la que entronca. Pensemos no sólo en las Cartas del Descubrimiento, sino en otras epístolas de resistencia rubricadas por nativos amerindios

un mismo colectivo de identificación junto con el sujeto de la enunciación, en un «nosotros» inclusivo $y$, por otro, a un paradestinatario, a quien está dirigido el arsenal persuasivo del discurso con el objeto de ganar su adhesión a las ideas y metas propuestas.

\section{7}

Entre esos escritos, se destaca La paz y la dicha del nuevo siglo, "exhortación dirigida a

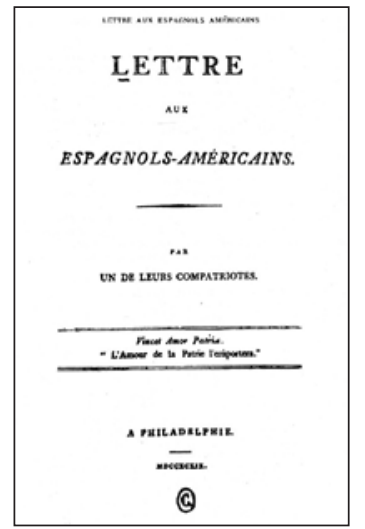

todos los pueblos libres o que quieran serlo, por un americano español," sobre el comercio exterior. Un extenso borrador de este tratado estuvo durante años inconcluso y fue concluido finalmente en 1797. Casi no quedan en este escrito huellas del patriotismo criollo que había profesado en sus textos anteriores; por el contrario, el autor se presenta aquí como un discípulo confeso de la llustración europea.

8 Como acota Brading (2004, p. 16), Rufus King sin duda se interesó en Viscardo por haber sido aquel un destacado político federalista y por la posición del peruano enfrentada a la revolución francesa. El estadounidense esperaba iniciar una intervención angloamericana en la América española para asegurar su independencia, ya que de no contar con el apoyo de Inglaterra, lo haría Francia, introduciendo sus principios $y$ dividiéndola en pequeñas repúblicas y concretando sus planes contra los ingleses. Con estas ideas, King entabló cordiales relaciones con Francisco de $\mathrm{Mi}$ randa, recién llegado a Londres, desilusionado por los acontecimientos en Francia y esperando recibir el apoyo británico.

Simmons encontró otras copias de la Carta entre los papeles del protector de Viscardo en el Ministerio de Asuntos Exteriores, sir James Bland Burges, quien los había depositado en la Biblioteca Bodleiana, en Oxford. En 1983 Simmons publicó los ensayos londinenses de Viscardo, también incluidos en los materiales de King conservados en Nueva York. Véase: Merle E. Simmons (1983).

\footnotetext{
La Carta a los españoles americanos, de Juan Pablo Viscardo. Aportes para el estudio del siglo XVIII hispanoamericano
}

MÓNICA ELSA SCARANO 
durante la conquista o en la misma Cartarespuesta a Sor Filotea de la Cruz de Sor Juana Inés de la Cruz, donde se despliega el dilema del letrado ilustrado entre razón, dogma y poder. Más precisamente, el texto epistolar que nos ocupa forma parte del «intrincado tejido de cartas» que recorrerá -al decir de Ángel Rama- todo el continente americano, «una compleja red de comunicaciones con un alto margen de redundancia y un constante uso de glosas» (1995, p. 47), aunque a diferencia de otras ésta no generará réplicas sino simplemente reproducciones y servirá de estímulo para esquelas emancipatorias posteriores.

Desde una perspectiva temático-argumentativa, la Carta se presenta aquí como una forma discursiva emancipadora y de resistencia, portadora de una conciencia crítica, que asume una función servicial (pedagógica y crítica a la vez), y se vincula con una serie de textos que proliferan en ese período -cartas, proclamas, manifiestos, pasquines, alegatos, arengas, periódicos, panfletos, sermones laicos, advertencias, declaraciones y otras «discursividades emergentes de un nuevo decir emancipatorio y letrado» (Hachim Lara, 2000 , p. 83), cuyo uso no era exclusivo de los líderes criollos. Ocupando un lugar central en el pensamiento hispanoamericano, que se le negó durante mucho tiempo, la epístola de Viscardo inaugura un tipo de reflexión encaminada a la búsqueda de una racionalidad inclusiva, alternativa, americana, combatiendo el colonialismo cultural, político y económico, ejercido por el gobierno español.

Pero hay en esta Carta una nota que la hace peculiar: Hachim Lara ve en ella una «estrategia de la subjetividad» (2000, p. 84$)$. Ya desde el título se plantea su inscripción en el género epistolar. Sin embargo, la interpelación que ejerce esta proclama la coloca al mismo tiempo en una categoría transgenérica. En efecto, investido de la autoridad del saber ilustrado, enciclopédico, ético-religioso (recordemos las citas de autoridad -Montesquieu, Antonio de Ulloa- y las referencias a la independencia de las Colonias de la América del Norte y la Revolución Francesa), el sujeto de la enunciación inicia una alocución dirigida a sus «hermanos y compatriotas», como elige nombrar a sus destinatarios más explícitos en el encabezado del texto, esbozando una entidad cultural casi inédita, aún distante de ser concretada en el orden político. La Carta deviene así un discurso político emancipa- torio en el sentido moderno, que oficia de texto-base para futuros proyectos libertadores y forma sistema con otras anteriores y posteriores desde el punto de vista temáticoargumental.

Por el contrario, es difícil -si no imposible- reconstruir el intercambio al que pudiera haber dado lugar, en principio porque se publicó y difundió ya muerto su autor. Esa compleja red de interlocución no se establece solamente en relación con el poder español, sino también y al mismo tiempo con criollos, mestizos, indios y españoles que viven en Europa y no son gachupines ni chapetones.

Por otra parte, si -como sostiene Hachim Lara- «el acto performativo tiende a construir un narratario específico, que se involucra con el proyecto emancipatorio» (2000, p. 85), el sujeto de la enunciación es desde varios puntos de vista un sujeto inédito, consciente de su especificidad, no sólo por su condición de ex jesuita criollo, desterrado de su lugar natal, la que podría colocarlo en un entre-lugar: ni del lado del dominador ni del dominado. Sin embargo, elige presentarse como un «español americano» y desde esta opción enuncia un esbozo de una entidad supranacional, la Patria grande, en el marco de lo que Arturo Roig ha llamado el «discurso del nosotros» (1981), marcado gramaticalmente por la omnipresencia casi asfixiante de la primera persona del plural a lo largo de todo el texto, como cuando afirma ya en las primeras líneas de la Carta que «El Nuevo Mundo es nuestra patria, su historia es la nuestra, y en ella es que debemos examinar nuestra situación presente para determinarnos, por ella, a tomar el partido necesario a la conservación de nuestros derechos propios y de nuestros sucesores» (Viscardo, 2004, p. 73. La cursiva es nuestra).

$\mathrm{Al}$ identificarse el enunciador con el personaje del jesuita expulsado, proclama la urgencia de la liberación de la América española y se establece de este modo una interpelación fundada en un cúmulo de conocimientos propios de la cultura humanística en la que fue formado el autor. Hay aquí, como advierte con agudeza Hachim Lara, un sustrato ficcional en los modos discursivos desde el principio hasta el final (explicit) de la carta que escapa al esquema epistolar: el destinatario criollo de ese relato emancipatorio permanece siempre en el campo de la potencialidad, está siempre en formación como un sujeto posible, proyectado hacia un futuro que es 
imperioso construir. En este punto el discurso ingresa en un territorio dominado por la letra y la razón, propio de la secularización, en la medida en que se reconoce y promueve allí la lucha del sujeto moderno por superar prejuicios, rémoras y limitaciones para ganar la libertad necesaria para recrearse como un sujeto soberano y dueño de sí mismo (2000, pp. 87-88). Aquí Hachim Lara sugiere la cercanía del texto-proclama con una forma discursiva propiamente moderna como el ensayo $(2000$, p. 88 ). Nosotros preferimos plantearlo como una forma proto-ensayística que anticipa y prepara el advenimiento del ensayo propiamente dicho en el siglo XIX, ya libre de fórmulas retóricas ajenas, y enunciado por sujetos políticamente emancipados.

Hay que advertir, además, que en la Carta el discurso emancipador no se limita a lo meramente retórico; por el contrario, incita a la acción y pone énfasis en la denuncia histórica de tres siglos de coloniaje: el gobierno colonial es acusado de tiránico, opresor, usurpador, con una larga serie de improperios y figuras descalificatorias proferidas en tono creciente. Esto habilita la posibilidad de leerlo como un discurso político, ya en un sentido moderno, donde pueden distinguirse con claridad las diferentes zonas que distinguen este discurso (Verón, 1987) ${ }^{10}$. En efecto, el discurso despliega desde las primeras líneas un cuadro de situación donde prevalecen componentes descriptivos ${ }^{11} \mathrm{y}$ explicativos del presente y el pasado colonial ${ }^{12}$, para más adelante avanzar en prescripciones ${ }^{13} \mathrm{y}$ fórmulas programáticas orientadas a instalar en el lector la urgencia de concretar la independencia en esa instancia histórica precisa ${ }^{14}$.

Más allá de lo hasta aquí expuesto -insistimos-, existen otros factores coadyuvantes que hacen de esta carta un texto peculiar: personal y público a la vez. En verdad, la subjetividad allí construida incluye lo personal: no escribe solo un criollo sino un jesuita expulso y, en un plano no visible ni explícito, un peruano con problemas para regresar a su patria y obtener su herencia patrimonial. Además, el sujeto de la enunciación no se agota en su condición de revolucionario o de ex jesuita exiliado; efectivamente pesan en la Carta motivos privados de índole personal que enfrentan a Juan Pablo Viscardo así como a su hermano, al tiránico gobierno colonial español. Ambos habían hecho sus primeros votos en Cuzco y habían dejado el Perú en 1768, aún sin recibir tonsura, arrojados a un temprano y penoso exilio por el decreto de expulsión sumaria firmado por Carlos III ${ }^{15}$, episodio en el que nos detendremos en el próximo apartado. Durante su estadía en Europa creció en él el resentimiento hacia el gobierno español que lo había expulsado de su patria y que además le impedía volver para hacerse cargo de su herencia ${ }^{16}$. Su experiencia de informante $y$ conspirador en la Foreign Office, sumada a su desconfianza y su temor de ser perseguido y vivir bajo sospecha (Brading, 2004, p. 15), conforma un telón de fondo siempre presente en sus escritos y en su pensamiento, que nos revelan aspectos no siempre considerados en los estudios sobre esta centuria en nuestros países.

Es claro que el siglo XVIII hispanoamericano no se agota en la razón ni mucho menos en la hegemónica o imperial. La Independencia se va conquistando y tejiendo no sólo con

12

«Supuestos estos principios incontestables» (Viscardo, 2004, p. 75); «No se pueden observar sin indignación los efectos de este detestable plan de comercio» (p. 76); "Aplicando estos principios al asunto actual» (p. 85).

\section{3}

«Queridos hermanos y compatriotas, (...) los grandes ejemplos de vuestros antepasados, y vuestro valeroso denuedo, os prescriben la única resolución que conviene al honor» (Viscardo, 2004, p.
89); «Debemos hacerlo por gratitud a nuestros mayores» (p. 90); "Debémoslo a nosotros mismos por la obligación indispensable de conservar los derechos naturales» (p. 91); «No hay ya pretexto para excusar nuestra apatía» (p. 92).

\section{4}

«Descubramos otra vez de nuevo la América para todos nuestros hermanos, los habitantes de este globo (...). La recompensa no será menor para nosotros que para ellos» (Viscardo, 2004, p. 91); «No hay ya pretexto para excusar

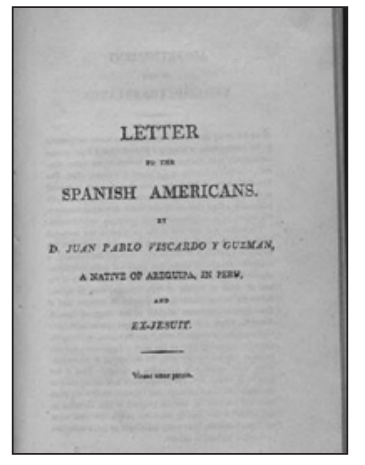

nuestra apatía...» (p. 92); «Este momento ha llegado: acojámosle con todos los sentimientos de una preciosa gratitud (...) la sabia libertad (...), seguida de la prosperidad comenzará su reino en el Nuevo Mundo, y la tiranía será inmediatamente exterminada» (p. 92); "Este glorioso triunfo será completo y costará poco a la humanidad» (p. 93).

15

Recordemos que, al arribar a Italia, los hermanos Viscardo dejaron la Compañía de Jesús, pasaron a ser laicos y se mantenían con una magra pensión cercana a la paga de un sirviente inferior, razón por la cual se vieron obligados a reclamar su parte de patrimonio paterno y el de un tío sacerdote. Por vía paterna, su bisabuelo era un español que se había asentado en esas regiones en 1630 y su abuelo se casó con una heredera de Pampacolca, en el valle del Majes, donde su familia tenía las haciendas. Pese a que los dos hermanos insistieron en el reclamo ante la Corona española tanto para que les permitieran regresar a su patria como para la liquidación judicial de su herencia, jamás obtuvieron respuesta.

16

Habiendo crecido Juan Pablo en la provincia de Arequipa y habiendo cursado estudios durante siete años en el Cuzco, donde pudo conocer el Perú auténtico, es comprensible que hablara el quechua (la lengua de los nativos). Existían además conexiones por matrimonio entre su familia y un linaje de indios kurakas. Esto sumado a su dominio del francés y el italiano, además del español naturalmente, lo convertiría -ya en Europa- en un calificado agente para la corona británica.

\footnotetext{
La Carta a los españoles americanos, de Juan Pablo Viscardo. Aportes para el estudio del siglo XVIII hispanoamericano
}

MÓNICA ELSA SCARANO 


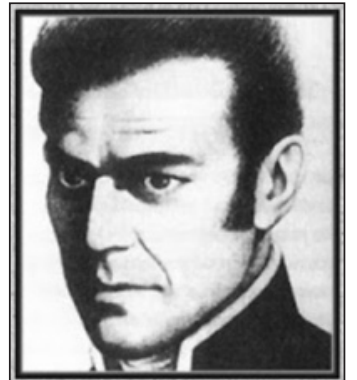

Juan Pablo Viscardo

\section{7}

Los jesuitas fueron brutalmente arrestados y enviados a un penoso exilio sin razón alguna, violando los derechos naturales de libertad y seguridad de las personas $y$ de sus bienes, lo que anticipaba de algún modo la futura confiscación de sus ricas propiedades. Los expulsados eran todos ciudadanos hispanos (europeos y americanos), de renombre por sus servicios a la comunidad, con grandes riquezas y muy estimados. Entre las causas no confesadas o, mejor, las excusas de la expulsión se impone su gran influencia en el continente americano. Carlos III tomó la decisión, incitado por ministros influenciados por enciclopedistas franceses, principalmente Voltaire y D»Alembert. Uno de ellos, Pedro Pablo Abarca de Bolea, Conde de Aranda, hábil y enérgico, llamado el «representante de Voltaire en España», indujo al rey español a firmar la Pragmática Sanción en contra de la Compañía de Jesús del 27 de febrero de 1767. Finalmente, el rey accedió a ordenar la expulsión de los jesuitas de América en abril de ese mismo año, luego de que los enemigos de esos clérigos lo persuadieran con una carta que fingía la acusación de que Carlos III no era hijo de su padre, Felipe $\mathrm{V}$, sino de un cardenal. Lo extraño fue que el monarca llevara adelante esa acción, siendo él mismo católico.

18

Ya antes de la expulsión del territorio americano, se había concretado una orden similar en Portugal y Francia. En América existieron antecedentes de la defensa de la libertad y la vida como derechos humanos inalienables. La primera expedi-

La Carta a los españoles americanos, de Juan Pablo Viscardo. Aportes para el estudio del siglo XVIII hispanoamericano

MÓNICA ELSA SCARANO

el telón de fondo de nuevas ideas y de una fría racionalidad política sino en un bastidor donde se entrecruzan también temores, resentimientos, urgencias y pasiones, no siempre confesadas públicamente. Por otra parte, es curioso observar cómo este despojo que conjuga el disimulado lamento personal con el explícito compadecimiento colectivo nos reenvía nuevamente a la correlación formal que mencionamos anteriormente entre las cartas indígenas y la que aquí nos ocupa: todas ellas comparten la situación de menoscabo y usurpación social, política y económica, y la desigualdad comunicativa. Leemos en la Carta: «...con nuestros tesoros inmensos no hemos comprado sino miseria y esclavitud» (Viscardo, 2004, p. 79), y "¿Qué maravilla es pues, si con tanto oro y plata, de que hemos casi saciado al universo, poseamos apenas con qué cubrir nuestra desnudez? (Viscardo, 2004, p. 76).

\section{La formación jesuítica de Viscardo y la idea de la independencia americana}

El episodio de la expulsión de los cinco mil jesuitas de los territorios monárquicos de América en $1767^{17}$ es mencionado en la Carta en reiteradas oportunidades con el claro propósito testimonial y de denuncia, pero también como un ejemplo contundente de la índole de la tiranía española ejercida en América: «La España nos destierra del mundo antiguo» (Viscardo, 2004, p. 75); «han desplegado de un golpe su irresistible eficacia sobre más de cinco mil ciudadanos Españoles» (p. 84); «Después de haberlos botado en un país, que no es de su dominación, y renunciádolos como vasallos, la Corte de España (...) se ha reservado el derecho de perseguirles y oprimirles continuamente» (p. 81), entre otras tantas alusiones ${ }^{18}$. Sin embargo, aunque en esos pasajes Viscardo se posiciona frente a la decisión de Carlos III de expulsar a los jesuitas de todos los vastos territorios de la monar-

ción al Perú de los jesuitas fue durante el reinado de Felipe II y las reducciones de Juli (de Belaúnde, 2002, pp. 57-58) Según Batllori, el germen de la idea independentista de los jesuitas expulsos fue el fermento de la idea cesionista entre ellos. Lo cierto es que hasta los no católicos y los enemigos de los jesuitas lo condenaron. Era conocido el encono de las monarquías borbónicas contra la orden de San Ignacio de Loyola, por los principios filosóficos tomistas y de otros discípulos sobre la soberanía popular, opuestos al absolutismo monárquico. Al mismo tiempo, fueron creciendo las presiones de esas

quía española, y critica que se los haya condenado a pasar el resto de su vida en Italia, en un penoso exilio, en ninguno de ellos explicita su relación pasada ni presente con la Orden de San Ignacio ni singulariza su experiencia, excepto por el «nosotros» que lo incluye y la aclaración de su condición de «ex-jesuita» que figura en la «Advertencia del Editor». De hecho no figuran ni él ni su hermano en la lista de jesuitas en el exilio italiano agregada por Miranda a las notas en su edición de la Carta, probablemente por haber renunciado ambos a la Orden. No obstante, no quedan dudas de la pertenencia de la epístola a la literatura de la diáspora jesuítica, un capítulo que complejiza aún más la caracterización de la producción literaria hispanoamericana del siglo XVIII y del entresiglo XVIII - XIX.

Por otra parte, es sabido que la presencia de los jesuitas y su intensa labor educativa incidieron fuertemente en la producción cultural de los dos últimos siglos coloniales, el XVII y el XVIII, en la América Hispana. En particular, en lo que nos incumbe, forman parte ineludible de un capítulo aún abierto y por explorar literatura del siglo XVIII hispanoamericano. Sin duda no se puede entender esta última centuria sin tener en cuenta su papel. Como sostiene Mario Hernández Sánchez-Barba:

En la elaboración de las estructuras culturales y mentales del siglo XVIII hispanoamericano, resulta fundamental el mundo de ideas creadas por la sensibilidad criolla del siglo XVII, la elaboración de un humanismo jesuítico que en el siglo XVIII fue en gran parte, heredero de las ideas elaboradas por ilustres miembros de la Orden en el siglo XVII (1978, p. 284).

Entre otros fenómenos destacables menciona el surgimiento de «un sentido crítico a distancia por los jesuitas expulsados y por sus discípulos universitarios, los criollos» (p. $284)^{19}$. En el marco de un denso proceso inte-

cortes para que la Santa Sede extinguiera la Orden hasta que el Papa Clemente XIV firmó el Breve de Extinción el 21 de julio de 1773.

\section{9}

Mario Hernández SánchezBarba menciona, además, entre otros factores que singulari- zan el «poco conocido y peor estructurado siglo XVIII hispanoamericano», la consideración de la polémica defensiva frente a las interpretaciones de los naturalistas europeos, y la aparición de una importante corriente de opinión pública, llevada adelante por los primeros periodistas (1978, p. 284) 
lectual la pervivencia del humanismo jesuítico había cobrado fuerza creciente entre las capas criollas ilustradas hispanoamericanas desde las Universidades y cobró importancia al crear una sensibilidad telúrica hispanoamericana y avivar la crítica racionalista e ilustrada, desde el exilio europeo.

La integración de los jesuitas en la sociedad criolla presenta una doble fase separada por la expulsión. El nuevo humanismo que ellos venían impulsando desde un siglo antes conformó un fenómeno cultural de gran importancia que cristalizó en el saber universitario de la primera mitad del siglo XVIII. La segunda fase consistió en la llamada literatura de emigración jesuitica, que abarcó distintas zonas con marcados matices, tanto en sus supuestos ideológicos como en la defensa de lo americano contra los naturalistas y filósofos europeos. En la segunda mitad del siglo, las nefastas implicancias político-administrativas de la Pragmática Sanción firmada por Carlos III en contra de la Compañía de Jesús se vieron agravadas por la violencia inhumana en el trato. Asimismo, entre sus múltiples consecuencias, se destacó la suspensión de una enorme tarea cultural en América.

En lo que concierne a nuestro autor, por su formación como religioso, es muy probable que conociera la corriente doctrinaria de pensadores españoles como el dominico Francisco de Vitoria, el escolástico Martín de Azpilcueta, Francisco Suárez, Juan de Mariana y otros, siguiendo las enseñanzas de Santo Tomás de Aquino (de Belaúnde, 2002, p. 49). En su horizonte de ideas estaba por un lado la tradición antiabsolutista y populista medieval, modernizada por Suárez durante el reinado del mismísimo Felipe II y puesta en práctica en América en la vida municipal de los cabildos, y, por otro lado, el choque con el absolutismo borbónico. En relación con este último, la expulsión de los jesuitas fue una de las acciones más impopulares en América, ya que en el conflicto los desterrados no habían sido meros espectadores, sino protagonistas (Batllori, 1953, p. 82). Nutridos por las concepciones de Aristóteles, la evolución contemporánea de hechos e ideas y la proyección de la noción de un estado orientado hacia la realización del bien común, los jesuitas objetaban el derecho divino de los monarcas y replanteaban la cuestión del origen de la autoridad, apoyados en la doctrina de la soberanía popular de Suárez. De este modo, el derecho natural cristiano se convertía fácilmente en una crítica intensamente revolucionaria de todas las relaciones de poder existentes, defendiendo la libertad y la igualdad. Podría decirse que, en este sentido, los filósofos y juristas mencionados se adelantaban a los pensadores ilustrados. Como se sabe, las tesis de los teólogos y juristas españoles Francisco de Vitoria y del padre Suárez son dos buenos ejemplos de las raíces ibéricas de la teoría moderna cristiana del estado. Todas estas teorías confluyeron junto con la tradición jurídica española de los Fueros y las Cortes (sobre todo la época gloriosa de las Cortes de Aragón, Navarra y Castilla) y abrieron caminos diferentes a los del pensamiento protestante (de Belaúnde, 2002, p. 52). Mariano Picón Salas destaca aquí la existencia de un «idealismo moral español» que integra lo ético y lo social (1978, p. 66).

Es evidente que el hecho de que Viscardo integrara las filas de los jesuitas exiliados no es una circunstancia aleatoria. Si bien, como ya se ha anticipado, durante mucho tiempo se otorgó un lugar decisivo a situaciones personales, no hubo siempre acuerdo sobre los factores más influyentes: Batllori otorga mayor peso al resentimiento que Viscardo seguramente experimentó por su injusto destierro y las difíciles circunstancias en que vivía, impedido de regresar al Perú. Por otra parte, agrega que el tener noticia del levantamiento de Tupác Amaru incentivó su rebeldía independentista. Desestimando estas posturas, de Belaúnde refuta la conjetura del estudioso catalán, aduciendo que ya antes de enterarse de esa rebelión, Viscardo había manifestado una posición ideológica y un propósito muy claros al respecto. En los catorce años de destierro, transcurridos desde su partida del Perú hasta 1781, cuando tomó conocimiento de ese hecho, ya había forjado un pensamiento al respecto a través de lecturas y de su formación jesuítica. En todo caso -arriesga el investigador peruano-, la noticia operó como un detonante para que se pronunciara el ideólogo (2002, pp. 46-55).

En resumen: la expulsión fue un elemento que facilitó el movimiento de la Independencia y colaboró en la búsqueda de una conciencia americana. Entre los efectos contradictorios de la proscripción, suele señalarse que obligó a los mestizos a comprometerse para avanzar en la acción emancipadora, sin que eso significase anular las ideas subversivas del clero más progresista sino todo lo contrario. En relación con
La Carta a los españoles americanos, de Juan Pablo Viscardo. Aportes para el estudio del siglo XVIII hispanoamericano

MÓNICA ELSA SCARANO 
20

El crítico chileno Luis Hachim Lara toma este concepto del filósofo argentino Arturo Andrés Roig, quien lo desarrolla en $A$. A. Roig (1984, p.16).

21

"Dictamen de los calificadores del Santo Oficio», en J. P. Viscardo y Guzmán (2004), Carta dirigida a los españoles americanos, Traducción, prefacio e introducción de David Brading, Apéndice II, p. 110.

22

Según los calificadores de la lnquisición, los frailes dominicos Luis Carrasco y José Bárcenas, en ese texto Viscardo incurría en un "paralogismo», por cuanto admiraba el valor de los primeros conquistadores y al mismo tiempo calificaba a los posteriores de ladrones. Además preveían que la Carta sería un instrumento sedicioso y subversivo que contribuiría a sublevar y fomentar la rivalidad entre hijos y padres, y criollos y gachupines. Por otra parte, dado el fanatismo mexicano con respecto a los jesuitas, la imagen de éstos proyectada en la epístola, de inocentes perseguidos, la tornaba aún más peligrosa (Brading, 2004, pp. 9-10).

23

En verdad, las repercusiones del reinado ilustrado y reformista de Carlos III, iniciado en 1759 , no fueron sólo económico-administrativas sino que alcanzaron también la vida intelectual y funcionaron como catalizadores en la formación de una identidad criolla en Hispanoamérica. Propició una verdadera «revolución intelectual» que transformó la cultura académica hispánica hacia el fin del siglo XVIII.

24

Pedro Henríquez Ureña le concede en esa época una importancia decisiva a la influencia de lecturas europeas, de las actas de independencia de recientes naciones americanas $y$ otros libros que circulaban, en muchos casos en forma clandestina (1986, pp. 39 y 52 ).

La Carta a los españoles americanos, de Juan Pablo Viscardo. Aportes para el estudio del siglo XVIII hispanoamericano

MÓNICA ELSA SCARANO

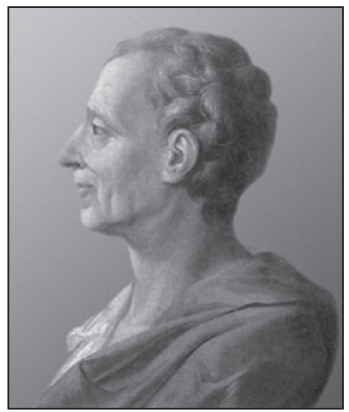

Retrato de Montesquieau, 1728

pios europeos. Los jesuitas exiliados sumaron su aporte a la acción de los criollos y contribuyeron a la formación de un Humanismo Ilustrado (Hachim Lara, 2000 , p. 79 ${ }^{20}$. En este sentido, fueron, desde la perspectiva de José Luis Romero, la expresión católica del espíritu moderno (1977, pp. IX-XXXVIII). Una muestra de ello fue la sospecha y la persecución que despertó el texto de Viscardo en algunos lugares de América. La suerte de su difusión en México es paradigmática al respecto: el 24 de setiembre de 1810, la Inquisición mexicana hizo público un edicto sumario donde se prohibía un cuadernito que circulaba con el título Carta dirijida a los españoles americanos por otro de sus compatriotas, y ordenó la confiscación de todas sus copias. En el dictamen de los dos dominicos que oficiaron de calificadores, se condenaba la carta por «falsa, temeraria, impía y sediciosa», «acre y mordaz, revolucionaria y sofística» ${ }^{21}$. En verdad, lo que más preocupaba de ella eran las acusaciones al gobierno colonial de España, concentradas en cuatro sustantivos con una carga fuertemente negativa, al afirmar que España había gobernado sus imperios de ultramar con «ingratitud, injusticia, servidumbre, y desolación» (Viscardo, 2004, p. 73)22. Sin embargo, pese a que la Inquisición condenó ese texto en octubre de 1812, un grupo de criollos residentes en la ciudad de México, los Guadalupes, que apoyaban en secreto la insurgencia, le hizo llegar una copia a José María Morelos, líder del movimiento insurgente en el sur. En consecuencia, la circulación del panfleto de Viscardo alarmó seriamente a la Inquisición, al ser la primera demanda pública por la independencia, proveniente de un español americano.

\section{La «Carta...» y la tradición ilustrada en la América Hispana}

En cuanto a la formación doctrinaria e ideológica de Viscardo, si buscamos las fuentes que originaron su pensamiento revolucionario, éstas no se encuentran ni en la Revolución Francesa ni en la rebelión de Túpac Amaru ${ }^{23}$. Nada de ello basta para explicar su pensamiento. Reiteramos que cuando Viscardo tomó conocimiento de esta noticia en 1781, ya había manifestado poseer una ideología arraigada al respecto ${ }^{24}$. Por cierto, el pensamiento de Viscardo se formó ocho años antes de la Revolución Francesa, diez años antes de que Francisco de Miranda comenzara sus actividades revolucionarias, unos doce antes de que Antonio Nariño fuera encarcelado en Nueva Granada por la publicación de los Derechos del Hombre y trece antes de que Santiago F. Puglia publicara en una imprenta de Filadelfia sus diatribas contra la monarquía española (De Belaúnde, 2002, p. 73). Habría que buscar las fuentes de su pensamiento revolucionario en lo que Arturo Andrés Roig caracterizó como el bumanitarismo ilustrado, con límites propios en América y que va más allá del aspecto economicista y utilitario del ideario ilustrado, manifestado en cifras, estadísticas y argumentos económicos, que abundan en la Carta.

Sin duda, la expulsión operó como una motivación psicológica importante para sus escritos independentistas. Formado en los principios filosóficos cristianos opuestos a la crueldad y la injusticia, con los que tomó contacto en el colegio de los jesuitas, durante su noviciado, tras algunos años en Italia, desde su exilio, se trasladó a Londres donde estudió las doctrinas económicas de la Ilustración europea. Los maestros británicos de la palabra se sumaron a la formación provista por Loyola. Durante su exilio también continuó su formación como autodidacta. Entre las fuentes de las que se nutrió, se destacan la filosofía política del siglo XVIII en la que definieron el destino revolucionario las obras de Montesquieu y Rousseau, ya influido por los filósofos católicos españoles, además de la lectura del ensayo del inglés John Locke, de gran influjo en el pensamiento de su época por su defensa de la libertad, el ideal democrático, la tolerancia en el pensamiento político, entre otras ideas que contribuyeron a la independencia de la América del Norte, sobre todo la Declaración de Filadelfia. Aquí podemos encontrar los argumentos por los cuales Viscardo condenaba tempranamente el absolutismo español. En síntesis: doctrinariamente ecléctico -como lo describe César Pacheco Vélez (1975)-, concilió distintas doctrinas 
que colaboraron con su causa revolucionaria, tal como lo muestran en la Carta las citas explícitas y alusiones más o menos veladas (Antonio de Ulloa, el Inca Garcilaso de la Vega, Montesquieu, Bartolomé de las Casas, y paráfrasis o resonancias de Montesinos, Raynal, Thomas Paine, entre otros).

Teniendo en cuenta que la Ilustración es «un estado de conciencia que canalizó las inquietudes intelectuales minoritarias mediante el impulso de la crítica centrada en dos puntos básicos de anclaje: la comprensión racional de las cosas y la desvinculación consciente del más allá...» (Hernández Sánchez-Barba, 1978, p. 286), sin que ninguno de los dos represente un aporte excluyente, podemos asegurar que el efecto de este proceso ideológico basado fundamentalmente en la razón ya se había hecho explícito en sus comentarios críticos sobre el catolicismo romano y español. Una carta dirigida a un colega ex jesuita de 1787 es el único texto donde abordó abiertamente la cuestión religiosa: allí criticó a los obispos y teólogos jansenistas del sínodo de Pistoia. Sin embargo, en su último tratado sobre la paz finalizado en 1797, objetó el despotismo civil religioso desmesurado y criticó los malos efectos de la religión en la conquista de América, sobre todo la superstición expresada en el fanatismo y la discordia. Su objeción no estaba dirigida allí solamente al uso político del catolicismo sino también a sus devociones. Al parecer hacia el final de su vida adoptó una versión más filosófica o ilustrada del cristianismo que se distanciaba de las pretensiones del papado ${ }^{25}$.

No cabe duda de que la Carta es el estudio mejor logrado de Viscardo, donde se combina - como afirma David Brading- la defensa de derechos ancestrales, propia del patriotismo criollo, con la proclamación de derechos universales característicos del credo ilustrado ${ }^{26}$. En cuanto a las remisiones a este sistema de creencias, es clara la resonancia de la Declaración de la Independencia de los Estados

25

No obstante, la Carta es un claro ejemplo de lo que sostiene Mario Hernández SánchezBarba sobre la llustración en América: «No existe, ciertamente, una ruptura decisiva entre el humanismo jesuítico y el humanismo ilustrado, puesto que, en ambos, existe una base antropológica del saber,

Unidos de 1776 y de la Declaración de los Derechos del Hombre de 1789. Se anticipó así por muchos años a la Revolución de la Independencia en el Perú y otras naciones del subcontinente que fueron, en última instancia, fruto de su prédica ideológica. Seguramente los vaivenes políticos que dominaron en esos años y las diferentes alianzas concertadas por las potencias europeas colaboraron en el proyecto libertador. Por cierto, si en un principio Viscardo fue un precursor y un patriota criollo, terminó siendo muy pronto -según Brading- un philosophe $e^{27}$ (2004). Se resistió a ver la América española con la mirada desdeñosa de otros ideólogos del Nuevo Mundo y defendió su personalidad peculiar y las cualidades criollas frente al menosprecio ilustrado.

Los componentes ilustrados de la Carta nos reenvían a una serie de cuestiones que nos permiten perfilar con mayor acierto el siglo XVIII latinoamericano: en primer lugar, el debate sobre la llegada de la Ilustración a Hispanoamérica -si en verdad eso sucedió-, cuándo tuvo lugar ese "desembarco", las particularidades de la llamada «Ilustración católica» y su papel decisivo en los territorios de ultramar, el fenómeno de la influencia de la Inquisición en la difusión de las nuevas ideas en esta orilla del Atlántico y, finalmente, la relación entre la Ilustración y los movimientos independentistas hispanoamericanos.

Si consideramos en términos generales el período ilustrado en América, es necesario aclarar de antemano que no se dio como en Europa, sino que fue más bien un deseo que una realidad:

La apropiación del pensamiento Ilustrado adquiere usos diversos y específicos en el hombre de letras americano y aún más, el período no coincide ni temporal ni paradigmáticamente con el homónimo europeo (...). En América, la historia de las ideas se benefició del pensamiento de muchos hombres de letras, que eran sacerdotes y al mismo tiempo luchadores por la causa de la libertad, como Hidalgo

Europa generó el sistema político del Despotismo llustrado Igobierno autoritario de los monarcas o de algunos de sus ministros). Este sistema pretendía realizar algunas reformas en el ámbito administrativo que reformularían la política y el comercio colonial en América. En otros órdenes, al mismo tiempo buscaba disi- par las tinieblas del dogma $y$ la autoridad, fomentar el pensamiento crítico, afirmando la razón y la libertad individual, en un sistema anticatólico y adverso a la Compañía de Jesús. En la Carta se apela explícitamente a la dialéctica de las luces («descubramos este horroroso cuadro para considerarle a la luz de la

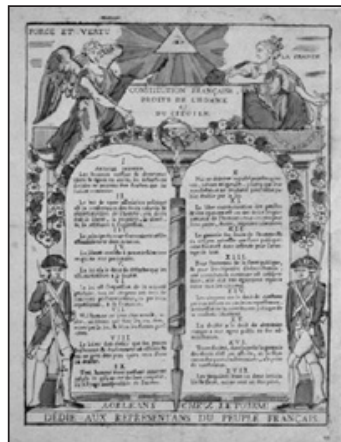

Declaración de los derechos del hombre

verdad» (Viscardo, 2004, $p$ 74)), y se alude tanto a los derechos naturales ( «La naturaleza nos ha separado de la España con mares inmensos» (p. 90) "por la obligación indispensable de conservar los derechos naturales» (p. 91)), como a los ancestrales («...nuestros antepasados, cuando restablecieron el reino y su gobierno, pensaron en premunirse contra el poder absoluto, a que siempre han as pirado nuestros reyes» (p. 82) «Debemos hacerlo por gratitud a nuestros mayores» (p. 90)), para argumentar a favor de la urgencia de lograr la emancipación política, económica y cultural de América.

\section{7}

Zygmunt Bauman agrupa en este concepto a "médicos, científicos, ingenieros, hacendados rurales, sacerdotes o escritores» que se leían mutuamente sus obras, hablaban unos con otros y compartían las responsabilidades de un juez colectivo, guía y conciencia de la especie humana» (Bauman, 1997, p. 38). Bauman destaca el papel de les philosophes de la era de la llustración en el proceso de autoconstrucción de los intelectuales modernos y su función en la memoria histórica viva de "utopía activa», en un «juego sin fronteras». No eran ni una escuela ni una comunidad de experiencia y educación; por el contrario, entre ellos se contaban personas de distintos estados y condiciones sociales (pp. 39-40). Eran, en suma, «un grupo autónomo que presentaba la opinión, la escritura, los discursos y el lenguaje en general como una atadura social para abolir todas las ataduras sociales» (1997, p. 40)

\footnotetext{
La Carta a los españoles americanos, de Juan Pablo Viscardo. Aportes para el estudio del siglo XVIII hispanoamerican
}

MÓNICA ELSA SCARANO 
28

Si por un lado, como sostiene Pedro Henríquez Ureña, «Entre las gentes educadas de la América hispánica hubo mucha afición por la lectura (...). En el siglo XVIII circulaban muchos libros de orientación moderna: la Encyclopédie, obras de Bacon, Descartes, Copérnico, Gassendi, Boyle Leibniz, Locke, Condillac, Buffon, Voltaire, Montesquieu, Rousseau, Lavoisier, Laplace se mantuvieron en circulación secreta todavía cuando se los consideró peligrosos y se prohibió su lectura» (1986, p. 39), a la par de la imposición del nuevo sistema del libre comercio en las colonias americanas, desde 1778, aún existía en algunas regiones del subcontinente cierta hostilidad a las ideas ilustradas (soberanía popular, anticlericalismo, entre otras), al mismo tiempo que en otras se abogaba por difundir el conocimiento científico útil y liberar el pensamiento filosófico de la escolástica. Otro ejemplo de las paradojas de este período es el intercambio transatlántico con el erudito benedictino Fray Benito Jerónimo Feijóo, uno de los más destacados exponentes del racionalismo en España que impulsó, ya entrado el siglo XVIII, un cambio hacia una actitud crítico-científica y predicó la flexibilidad mental.

29

Como se sabe, los comienzos de la llustración en España coincidieron con la llegada de la Casa de Borbón al trono. Pero la nueva ideología no desplazó totalmente de la escena a las corrientes escolásticas que, desde el siglo XVI y sobre todo desde las universidades de Salamanca y Alcalá de Henares, se habían propagado a las de Lima y México. Con la colaboración de los colegios jesuitas se otorgó cierta homogeneidad al pensamiento hispanoamericano de la época cuando apenas se hacían sentir en España aún débiles ecos del movimiento científico de la Europa del XVII. Véase: Ma. Angeles Eugenio Martínez (1988), La llustración en América (siglo XVIII): pelucas y casacas en los trópicos. pp. 34-ss. Por otra parte, como explica Mariano Picón Salas, «El cosmopolitismo del hombre europeo que ya no se satisface con su vida tradicional y sale por anhelo científico o por mera inquietud humana a recorrer distantes países y a someter sus valores se-

La Carta a los españoles americanos, de Juan Pablo Viscardo. Aportes para el estudio del siglo XVIII hispanoamericano

MÓNICA ELSA SCARANO

y Morelos en México. El encuentro de las dos vertientes de pensamiento, en la conformación difusa del proyecto autonomista y emancipatorio, se produce con el aporte de una Ilustración Católica (...), que propende a no disociar la razón y la fe y que por otro lado contiende con la filosofía escolástica en el interior de la misma institución de la Iglesia, recuperando aspectos del humanismo renacentista» (Hachim Lara, 2000, pp. 79-80).

En gran medida, el anticlericalismo dominante en esta corriente filosófica fue la causa de que no se reconociera como es debido el aporte de la ilustración católica, de innegable importancia en Hispanoamérica. La filosofía de la Ilustración se ocupó principalmente del proceso de secularización del pensamiento, pero dentro de ella, como hemos visto, los jesuitas se comprometieron paradójicamente en la ruptura de la episteme clásica. Pese a ser sacerdotes, muchos miembros de la Compañía participaron en forma activa en el debate intelectual de su tiempo. Esta variante del pensamiento ilustrado católico se distinguió de la emancipación hispanoamericana por sus raíces escolásticas, sin que se la pudiera negar ni soslayar, puesto que la ilustración americana tuvo lugar en un cruce heterogéneo de diálogos, rechazos e integraciones. ${ }^{28}$ Por otra parte, como lo vemos en el texto que nos ocupa, el pensamiento americano no remitió de un modo excluyente a la Ilustración francesa sino también a otras formas ilustradas marginales (españolas y portuguesas) que contribuyeron a explicar la compleja orientación católica y emancipatoria de este autor, que ilustra en cierto sentido la extrema tensión entre escolasticismo y enciclopedismo que atravesó el clima mental de la sociedad colonial (Picón Salas, 1978, pp. 199-200229.

Además, la apropiación de estas formas diversas de pensamiento contribuyó a crear una «conciencia criolla diferenciada» que se originó tempranamente durante la colonia y que se manifestó en el enfrentamiento entre peninsulares y españoles americanos (sus iguales nacidos en América de padres españoles,

culares al paralelo y contraste con el de pueblos más nuevos y hasta ese instante menospreciados; y el cosmopolitismo del criollo que siente en su cerrada órbita colonial la desazón del aislamiento y el gusto de po- seer las ideas y aplicaciones de la vieja Europa, son uno de los ingredientes que determinan hasta en la cultura hispanoamericana del siglo XVIII ese complejo estado de espíritu o actitud de conciencia que se ha llamados también criollos o indianos), acompañado de desigualdades y discriminaciones impuestas por el gobierno central español, lo que creó las condiciones materiales para el surgimiento de una conciencia crítica (Osorio, 2000, p. 72).

Hay, desde el orden textual mismo, otra particularidad en la Carta que reside en la importancia dual de la razón universal y de cierta subjetividad política en ciernes que trasunta una experiencia situada en un contexto determinado por el entendimiento y la apropiación del mundo, que se vincula con la soberanía de los pueblos: así a argumentos tales como la apelación a la verdad: «Esta nos enseña, que toda ley que se opone al bien universal de aquellos, para quienes está hecha, es un acto de tiranía...» (Viscardo, 2004, pp. 74-75), se le suman otros de esta índole: «aunque no conozcamos otra patria que ésta, en la cual está fundada nuestra subsistencia, y la de nuestra posteridad» (p. 74) o «si no hay entre vosotros quien conozca y sienta sus agravios más vivamente que yo...» (p. 89).

En relación con este último sentido, la reiterada argumentación a favor de la oportunidad de la independencia en esa coyuntura histórica, marcada por deícticos temporales, exhortaciones y verbos en futuro, se torna crítica áspera y sin concesiones a la Conquista, apelando a la fustigación del despotismo y la tiranía coloniales que alcanzan hasta la esfera económica: el estado de «ignominiosa esclavitud» (p. 74) y violencia en que se autorretrata se completa con la denuncia del «más desenfrenado monopolio» en una verdadera «tiranía mercantil» (p. 76). Es esto lo que habilita la estrategia de adoptar un tono panfletario que se hace evidente en los adjetivos calificativos bien elegidos como dardos certeros y las figuras denigratorias de los contradestinatarios del texto (entre otros, los funcionarios españoles que ejercían el poder injustamente y sin piedad). Se los describe como «un enjambre de aventureros, que pasan a la América, resueltos a desquitarse allí, con nuestra propia sustancia, de lo que han pagado para obtener llamado «Enciclopedismo» ○ «llustración»» (1978, p. 197) A diferencia de la contrarre forma y el barroco, se abrió en el siglo XVIII "una nueva época internacional» (p. 197) que asistió a un «avasallador choque de ideas», junto a un conflicto generacional y una atmósfera de creciente insurgencia, marcada por el ascenso de criollos y un creciente resquemor indiano frente a los peninsulares (pp. 199-200). 
sus empleos» (p. 78), «orgullosos tiranos» (p. 78), sin límites, perversos y obstinados, que exterminaron de la superficie de la tierra a pueblos enteros ${ }^{30}$. Junto a la denostación de éstos y de su mal gobierno, se avanza en la defensa de los criollos, mestizos e indios ${ }^{31}$. A su vez, con la argumentación mediante citas de autoridad tomadas, por ejemplo, de la obra del Inca Garcilaso de la Vega, oponiéndose a la privación de participar en el gobierno de sus propias tierras ${ }^{32}$. Viscardo se inscribe en una tradición de protestas criollas patrióticas, pero es importante advertir que su condena de la monarquía absoluta de los Habsburgo y los Borbones significaba un paso más allá de las quejas tradicionales del patriotismo criollo.

La condición interpelativa y el didactismo del texto abren paso a un discurso político de crítica y resistencia frente a la filosofía escolástica. Reforzado por un discurso pedagógico en la línea del Padre Feijóo, que acompaña la denuncia, buscando ilustrar e iluminar al español americano para enjuiciar el poder colonial y revisar críticamente sus prácticas, a poco de iniciada la proclama se instala claramente la verdad: «descubramos este horroroso cuadro para considerarle a la luz de la verdad. Esta nos enseña que toda ley que se opone al bien universal de aquellos, para quienes está hecha, es un acto de tiranía» (Viscardo, 2004, p. 74). En esa construcción apela también a pensadores coetáneos y testigos oculares como Antonio de Ulloa, coautor de un informe que escribió con Jorge Juan, Noticias secretas de América (1747), para certificar su denuncia de condiciones paupérrimas de los americanos en general con argumentos acordes a las reglas de la razón. En ese esfuerzo verificador recurre a afirmaciones como la de Montesquieu: «Las Indias y la España son dos potencias bajo un mismo dueño; mas las Indias son el principal y la España el accesorio» (Viscardo, 2004, p. 81).

\section{Proyecciones hacia el XIX hispanoamerica- no: la literatura de la Emancipación}

El intenso valor polémico de la Carta, propio de un texto agonístico inmerso en la pragmática de un conflicto (Hachim, 2000, p. 92), así como su evidente imbricación con la temática emancipatoria ${ }^{33}$ y su función activa en el proceso histórico concomitante en América, nos permiten revisar su inclusión en la llamada «literatura de la Emancipación hispanoamericana». Al respecto, la ubicación de este tramo del siglo XVIII varía según los autores -ya incluyéndolo en el concepto amplio de «cultura colonial» (Pedro Henríquez Ureña, 1986; entre otros), ya incorporándolo entre las «letras de la emancipación», en una primera etapa del siglo XIX (1791-1830) (Picón Salas, 1978; Osorio, 2000)-, y pone de relieve la arbitrariedad señalada por Ana Pizarro en la periodización de la historiografía literaria latinoamericana por siglos o con criterios histórico-políticos externos ${ }^{34}$. Sin desestimar los aciertos descriptivos de estas proposiciones, nos inclinamos por ver también en esa parte del siglo XVIII una prime-

30

También leemos en la Carta: "Sería una blasfemia el imaginar que el supremo bienhechor de los hombres haya permitido el descubrimiento del Nuevo Mundo para que un corto número de pícaros imbéciles fuesen siempre dueños de desolarle, y de tener el placer atroz de despojar a millones de hombres, que nos les han dado el menor motivo de queja, de los derechos esenciales recibidos de su mano divina» (Viscardo, 2004, p. 91).

31

Al referirse a fortunas hechas sobre el maltrato hacia los nativos, los evoca como «pobres indios, nuestros compatriotas» (p. 87), y cuando denuncia las atrocidades de los repartimientos se conduele de la de- solación y la ruina de «los desgraciados indios y mestizos" (p. 76). Del mismo modo, a criticar a virreyes, corregidores y alcaldes mayores europeos, que actúan como aventureros injustos que trafican injusticias e inhumanidades «de parte de las sanguijuelas empleadas por el gobierno» (Viscardo, 2004 p. 79). En este punto, sus críticas e interpelaciones buscan despertar la desconfianza criolla hacia los españoles peninsulares y atizar su resentimiento por la condición colonial, en tanto que elogia las libertades ganadas por las cortes medievales y ataca el absolutismo Melchor de Jovellanos y Francisco Martínez Marina, juristas que alabaron la antigua Constitución española y buscaron reformar la monarquía por el real, anticipándose a Gaspar retorno a las instituciones y libertades medievales (Brading 2004, p. 38).

\section{2}

En la cita de los Comentarios Reales del Inca Garcilaso, Viscardo se manifiesta fuertemente en contra del primer representante del nuevo poder arbitrario de la Corona: el virrey Francisco de Toledo, a quien describe como un «monstruo sanguinario» (Viscardo, 2004, p. 81) que capturó al primer heredero del imperio inca, "el joven e inocente Inca Túpac Amaru» (2004, p. 79) y lo asesinó tras un falaz proceso judicial. Allí se explaya sobre la persecución y las torturas de ese virrey hacia los jóvenes mestizos de Cuzco, hijos de conquistadores españoles y princesas incas, acusados de apoyar a los rebeldes. La cita le permite también referir el destino de sus desventurados compatriotas, asociando la causa de los españoles americanos con el destino de los mestizos de Cuzco, y manifestarse en contra del arbitrario régimen colonial introducido por el Emperador Felipe II y su subordinado, el virrey Toledo. Para ilustrar la tiranía real, como se dijo, la expulsión de los jesuitas ocupa en la Carta un lugar preferencial, en una larga y detallada lista de atropellos de diferente índole, tales como el aumento de los impuestos tan resistido por los españoles americanos, el reclutamiento de una milicia en las Indias y la ampliación de la armada española con rentas del Nuevo Mundo. Debe notarse, además, que el sustento argumentativo de la crítica a la colonia y en particular de la tiranía ejercida en ese período, no se basa en las citas de autores clásicos como Aristóteles o Santo Tomás de Aquino, sino en argumentos económicos como el monopolio comercial, los impuestos excesivos que gravaban el comercio con América y el opresivo repartimiento de comercio implementado por los nefastos corregidores.

33

En este sentido, merece llamarse la atención sobre la formulación utópica del remate final de la Carta, donde aboga por una América española que sea punto de encuentro de toda la humanidad. Así la epístola se convierte en un instrumento político poderosísimo que se dirige con distintas voces y variados argumentos, a lectores muy diferentes. Prefigurando la utopía del siglo XIX, ve a hombres de todas las naciones frecuentando las costas de América, atraídos por el libre intercambio de los productos Erradicados el despotismo y la pobreza, imagina a estos hombres radicándose en la América española para enriquecerse con la industria, los conocimientos y el aumento de la población americana. América se uniría a patrias más lejanas y sus habitantes formarían "una sola GRANDE FAMILIA DE HERMANOS» (Vis cardo, 2004. p. 94), en consonancia con la euforia cósmica dominante en la imaginación europea en las primeras etapas de la Revolución Francesa.

34

En relación con la periodización de la historia literaria por siglos, en una perspectiva cronológica, Ana Pizarro explica que "esta forma de organización presenta el inconveniente de simplificar el esquema sin aportar un conocimiento sobre las modulaciones que adopta el discurso en proceso, sobre sus rupturas y sus continuidades en términos de producción literaria.» (2005, p. 28). En cuanto a la organización por cortes de la historia política tales como la Independencia o la Colonia, la crítica chilena sostiene que "ella no explica el proceso mismo sino que lo remite a cortes externos. Estas situaciones externas desde luego lo condicionan, lo sitúan; frente a ellas la literatura entrega una respuesta, pero no necesariamente le corresponden como rupturas propias (1985, p. 29).

\footnotetext{
La Carta a los españoles americanos, de Juan Pablo Viscardo. Aportes para el estudio del siglo XVIII hispanoamerican
}

MÓNICA ELSA SCARANO 


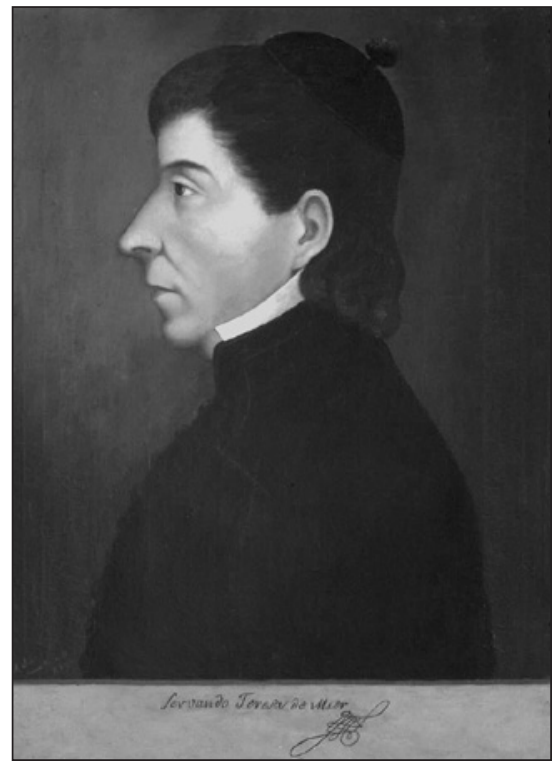

Retrato fray Servando Teresa de Mier

35

Es difícil precisar el impacto de la Carta sobre los hombres que promovieron y lucharon por la independencia de la América española. Se sabe que fue leída con entusiasmo por los venezolanos Pedro Gual y Francisco. de Miranda, también por el rioplatense Mariano Moreno, quien siendo abogado en Chuquisaca tradujo la edición francesa al español. Además, se sabe que el patriota e ideólogo mexicano fray Servando Teresa de Mier poseía una copia de la Carta.

La Carta a los españoles americanos, de Juan Pablo Viscardo. Aportes para el estudio del siglo XVIII hispanoamericano

MÓNICA ELSA SCARANO ra etapa insoslayable del proceso literario de la Revolución de la Independencia de América Latina, destacando sobre todo el papel rector de ideólogos y precursores.

Volviendo a la epístola, más allá de la forma de la expresión, la perspectiva introducida por el sujeto ilustrado en esta primera proclama de la Emancipación hispanoamericana, como en otras cartas políticas de esta etapa (tal es el caso de la "Carta de Jamaica» de Simón Bolívar y las «Cartas de un americano al Español» de Fray Servando Teresa de Mier, entre otras), remite al relato de la emancipación tanto desde lo cultural como desde lo político y presenta un nuevo objeto: América como una sola Patria, propuesta que continuarán patriotas de la talla de Miranda y Bolívar. En este sentido, no puede negarse la importancia de este texto y de otros escritos menos conocidos de Viscardo para los planes independentistas. En efecto, la Carta es el primer manifiesto célebre que abogó abiertamente por la independencia de las Indias, con argumentos sólidos y razones evidentes, y durante dos lustros fue el instrumento más utilizado por Miranda en su acción revolucionaria y tal vez el más eficaz por la amplia repercusión que al parecer tuvo en el ambiente intelectual de los criollos hispanoamericanos revolucionarios, sirviendo además como modelo a muchos escritos inspirados en ella, desde México hasta Argentina y Chile, lo que colocó a su autor definitivamente en el papel de ideólogo y precursor de la nación, de la independencia y la solidaridad continental ${ }^{35}$. En su áspera crítica a la época colonial en bloque, fue además precursor del liberalismo decimonónico que menospreciaba los tres siglos de dominio despótico hispano, en busca de la concreción de una utopía propia.

A modo de conclusión, podemos afirmar que, en el siglo XVIII, cuando el mundo hispánico vivía ya bajo la sombra de los modelos externos y veía en los Estados Unidos un referente paradigmático, en esa coyuntura, Juan Pablo de Viscardo y Guzmán se perfila como un precursor e ideólogo de la emancipación, la que sería un lugar común en el siglo XIX y no se cumpliría en América de manera uniforme sino con una dinámica propia según las distintas situaciones locales, irreductible a la de los procesos europeos coetáneos (Romero, 1977, p. IX). Con la libertad como condición indispensable del proyecto emancipador, un apasionado fervor utópico ante el futuro y una acendrada causticidad para juzgar el pasado, Viscardo realizó un importante aporte a la tradición nacional peruana, irrumpiendo así con su palabra intempestiva a fines de esa centuria como testigo profético del patriotismo criollo y de la clausura del período colonial.

\section{Bibliografía}

Batllori S. J., Miguel (1953), El abate Viscardo. Historia y mito de la intervención de los jesuitas en la independencia de Hispanoamérica, Caracas, Instituto Panamericano de Geografía e Historia.

Brading, David (2004), «Prefacio» e «Introducción: Juan Pablo Viscardo y Guzmán, patriota y philosophe criollo», en Juan Pablo Viscardo y Guzmán, Carta dirigida a los españoles americanos, México, FCE.

De Belaunde Ruiz de Somocurcio, Javier (2002), Juan Pablo Viscardo y Guzmán. Ideólogo y promotor de la independencia hispanoamericana, Lima, Fondo Editorial del Congreso del Perú.

Eugenio Martínez, María Ángeles (1988), La Ilustración en América (siglo XVIII). Pelucas y casacas en los trópicos, Madrid, Anaya - Biblioteca Iberoamericana.

Hachim Lara, Luis (2000), «La Carta a los españoles americanos (1791) del abate Viscardo y la tradición crítica en América», en Tres estudios sobre el pensamiento crítico de la Ilustración americana, Prólogo de Nelson Osorio, Murcia, Universidad de Alicante - Universidad de Santiago de Chile, Cuadernos de América sin nombre, pp. 75-110.

Henríquez Ureña, Pedro (1986), Historia de la cultura en la América Hispánica, México, FCE.

Hernández-Sánchez Barba, Mario (1978), Historia y literatura en Hispanoamérica (14921820). La versión intelectual de una experiencia, Buenos Aires, Editorial Castalia.

Osorio, Nelson T. (2000), Las letras hispanoamericanas en el siglo XIX, Murcia, Cuadernos de América sin nombre.

Pacheco Vélez, César (1975), «Los ideólogos», en Colección Documental de la Independencia del Perú, Lima, V. 1. 
Picón Salas, Mariano (1978), De la Conquista a la Independencia. Tres siglos de bistoria cultural hispanoamericana, México, FCE.

Pizarro, Ana (1985), «Introducción», en A. Pizarro (coord.), La literatura latinoamericana como proceso, Buenos Aires, CEAL, pp. 13-67.

Roig, Arturo Andrés (1981), Teoría y crítica del pensamiento latinoamericano, México, FCE.

Roig, Arturo Andrés (1984), El bumanismo ecuatoriano de la segunda mitad del Siglo XVIII, Tomo I, Quito, Banco Central del Ecuador.

Romero, José Luis (1977), «Prólogo», en J. L. Romero y Luis Alberto Romero. Pensamiento político de la Emancipación (1792-1809), Caracas, Biblioteca Ayacucho, pp. IX-XXXVIII.

Simmons, Merle E. (1983), Los escritos de Juan Pablo Viscardo y Guzmán. Precursor de la Independencia Hispanoamericana, $\mathrm{Ca}-$ racas, Universidad Católica Andrés Bello.

Stolley, Karen (2006), «El siglo XVIII: formas narrativas, erudición y saber», en Roberto
González Echevarría y Enrique PupoWalker (eds.), Historia de la literatura bispanoamericana, I. Del descubrimiento al Modernismo, Madrid, Gredos, pp. 354390.

Vargas Ugarte S. J., Rubén (1954), La Carta a los españoles americanos de don Juan Pable Viscardo y Guzmán, Lima, Editorial del CIMP.

Verón, Eliseo (1987), «La palabra adversativa. Observaciones sobre la enunciación política,» en Eliseo Verón, Leonor Arfuch y otros, El discurso político. Lenguaje y acontecimientos, Buenos Aires, Hachette, pp. 11-26.

Viscardo y Guzmán, Juan Pablo (1998), Obra completa, 2 vols., Perey Cayo Córdoba y César Pacheco Vélez (edits.), Lima, Ediciones del Congreso del Perú.

Viscardo y Guzmán, Juan Pablo (2004), Carta dirïida a los Españoles Americanos, Traducción, prefacio e introducción por David Brading, México, FCE.

Fecha de recepción: 20/02/2013

Fecha de aceptación: 29/07/2013
La Carta a los españoles americanos, de Juan Pablo Viscardo. Aportes para el estudio del siglo XVIII hispanoamericano

MÓNICA ELSA SCARANO 